\title{
SIMULATION OF TRACK VEHICLE PASSABILITY
}

\author{
Milan Chalupa, Josef Veverka \\ J. E. Purkyne University in Usti nad Labem, Czech Republic \\ milan.chalupa@ujep.cz, josef.veverka@mscsoftware.com
}

\begin{abstract}
The paper describes the vehicle passability testing possibilities using computational simulation system ADAMS AVT. The vehicle passability is one part of the vehicle handling. The vehicle passability simulation calculations can quickly and cheaply help come up with the answers on basic and supplementary questions on the design influence changes in the area of car properties testing. The aim of the simulations is to acknowledge the possibility of the usage of analysis simulation results for the investigation of passability of a tracked vehicle. These simulations were executed with the help of computing system Adams AVT. The simulation and analysis results described riding of a tracked vehicle BMP 1 uphill. Terrain vehicle passability given by stair step up ability, ditch traverse ability, by the ability of vehicles to surmount definite angle of gradient, fordability or deep fording ability is given by the vehicle design. It is useful to have some more information, the influence of what might change the ability of the vehicle overrule a definite angle uphill, for example. It can be information, how it is possible best to affect the vehicle ability to fetch through obstacles with low adhesion or else. The simulation calculations can help find quick answers to basic and additional questions of the design change influences at the area of testing the vehicle passability. The first part of the article contains a description of partial computation simulation model construction, which the calculations are associated with. The binding conditions of calculations are mentioned also. In the second part of the article there are the results of performed simulation calculations mentioned and evaluated. These calculations are performed in order to find out the influence of the operation conditions on the vehicle passability. Real operation conditions are the invasive vehicle speed into a slope in this case. They are the input data of simulation. Under investigation is the change of the maximum beaten distance uphill that the vehicle is able to overcome. They are the output data of simulation.
\end{abstract}

Keywords: simulation, computational modeling, testing of passability.

\section{Introduction}

The track vehicle handling can be tested in several ways. The handling test conducted on the vehicle prototype is the most exact way how to perform it. However, also the most expensive. Another option is to conduct the test on a faithful car model, where the cars are made under certain scale reduction in comparison with real sizes. All inaccuracies of the test results are directly proportional to the rate of the sizes of a smaller model to a real vehicle. Financial claims are in this case fundamentally lower. The third possibility of the vehicle handling test is the usage of a computer simulation. The computer modeling and the process of simulation, affecting the mechanical system, is an effective instrument how to investigate dynamic properties of mechanical systems [1;2]. It is possible to benefit here from the computation simulation systems [3]. Comparing the tests on a real prototype or a smaller model, the indisputable benefits are the time and financial savings. Further advantages are simplicity of computation data setting, high flexibility setting possibilities of tested cases, high speed and promptitude of all calculations [4]. Moreover, an advantage is also error elimination caused by the human factor [5]. Also, by drawing up well-arranged and objective numeral and graphic output it is possible to obtain susceptibly good comparability of the results [4;5]. In order to utilize these advantages, it is necessary to optimize the mathematical model of the analysed mechanical system [2]. It means, it is necessary to determine accurately, how sophisticated must the model be in order to answer our questions. In most cases, it is sufficient to make up only a simple model $[6 ; 7]$. We should be satisfied, when the first simulation result will give us only simple and often primary information [8]. The simple model is sufficient for our inspiration and narrowing down correct direction for the next procedure. This simple model includes essential elements of interest and, exclusively, mechanical system bindings. There must be the most considerable static forces and load torque of the mechanism as well [7]. The aim of the model preparation is to complete the model, which describes the system under examination, most accurately [9].

The vehicle passability is one part of the vehicle handling. The vehicle passability simulation calculations are helpful in finding the answers on basic and supplementary questions on the design influence changes by car properties testing. Terrain vehicle passability given by ditch traverse ability, stair step up ability, by the ability of vehicles to surmount a definite angle of gradient, fordability or deep fording ability is given by the vehicle design. It is usefull to have some more information given 
by the projection of a new track vehicle. For example, there is information, the influence of which might change the ability of the vehicle to overrule a definite angle uphill. Furthermore, there is information how it is possibly the best way to affect the vehicle ability to fetch through obstacle swith low adhesion or else. These items of track vehicle driveability can be influenced by the height of the vehicle, weight, vehicle centre of gravity, by the height of the track rib shape or invasive speed of the vehicle by riding uphill. The vehicle ability to surmount a climb will be influenced by the adhesion coefficient betwen the track and the ground by the vehicle riding. We can find the answers inexpensively and quickly by using computational simulating systems, as ADAMS AVT is, for example.

The main aim of the article is to acknowledge the possibility of usage results of simulation calculations of the vehicle construction. These simulation results are gained by using computing simulating system ADAMS AVT. The simulating calculations were done to find out the influences of the vehicle construction part changes or operation conditions. The operation conditions can be represented by the invasive vehicle speed, the angle of roadway gradient uphill or values of the adhesion coefficient. Under investigation can be abilitity of a vehicle to achieve the biggest angle, while riding the vehicle into slope uphill and travelling the biggest distance by uphill riding.

Computational simulation of the tracked vehicle BMP 1 riding is described in the next part of the text. The riding conditions can be driving uphill by an uncertain angle of gradient by a constant value of the adhesion coeficient. The calculations can be performed by computing system ADAMS AVT and mathematics models of the hull and vehicle chassis of the vehicle BMP 1 . The mathematical models are different for the terrain and the models of the vehicle speed. The models will be described as follows. The calculations are designed on the ground of the parameter calculations input values setting. Input values can be the driving wheel angular velocity, the angle of roadway slope and the adhesion coeficient value.

Defined range of the vehicle speed is computationally described by the setting of the angular speed of the driving wheel. This speed defines the changes of the invasive vehicle speed uphill. The character of the roadway changes are described by the way of the adhesion coefficient changes and the raising of the roadway slope changes. There are main influences of changes of the riding velocity of the vehicle and the character roadway on the ability of the vehicles to surmount a definite angle of gradient. It is conducted by using the analysis results of simulating calculations of monitored parameters. The monitored parameters can be the angle of incilation of the roadway and the distance travelling to the moment of full sliping vehicle tracks and full stopping of the vehicle hull movement.

This paper describes one part of simulation calculations that observed simulation of the influence of changes of the invasive vehicle speed changes by ridding to slope uphill on the achieved roadway maximum vehicle distance to the moment of stopping the vehicle hull movement for loosing of the track adhesion.

\section{Materials and methods}

The computational system ADAMS AVT is used for computational modelling and simulation. This system can be used for the analysis of kinetic and dynamic characteristics of modelling a mechanic system and its animation also. The computational model consists of geometrical and contact parts of the model.

The geometrical part of the computational model consists of the basic parts of the vehicle undercarriage movable organs (road wheels, supporting rollers, driving sprocket, idle wheel). The main part is the track line, on which individual track links are connected by couplings.

The contact part of the computational model consists of impact and frictional forces systems. To guarantee the highest accuracy the impact and frictional forces of individual undercarriage parts are defined in such a way that the whole model resembles the reality as much as possible.

\section{Partial models for simulation calculations}

Eight partial computing models for completing of the basic mathematical simulating model of the hull and the chassis of the BMP 1 vehicle were used. Consecutive simulating calculations were made with the help of the partial model. Speed models of the driving wheel, the roadway geometric models 
and contact models of the track link with the roadway were used. As a basic and major one, a geometric model of the design and the construction of the hull and BMP 1 vehicle chassis was used. There were used as the velocity models of driving wheel modes, the model of contact detection with roadway mode, the model of accelerating period mode and the model of constant speed mode. The following models were used: geometric model of roadway, elasto - plastic roadway model and plastic roadway model. The design of all used models is described in detail in the work [5] and [11]. All models were verified by the help of experimental measuring in 2009 and the verification measuring is described in [12]. The most important here are the geometric model of the roadway and the model of the roadway contact.

\section{Geometric model of roadway}

The roadway geometry is defined as the assembling of step by step the growing level system, which has a growing climbing angle. The geometric model design of roadway is introduced in Fig. 1.

\begin{tabular}{|c|c|}
\hline $\begin{array}{c}\text { Variant of } \\
\text { track } \\
\text { slope } \mathrm{N}^{\circ}\end{array}$ & $\begin{array}{c}\text { Angle of } \\
\text { track } \\
\text { slope }\left[^{\circ}\right]\end{array}$ \\
\hline 1 & 20 \\
\hline 2 & 22 \\
\hline 3 & 25 \\
\hline 4 & 28 \\
\hline 5 & 30 \\
\hline 6 & 32 \\
\hline 7 & 35 \\
\hline
\end{tabular}

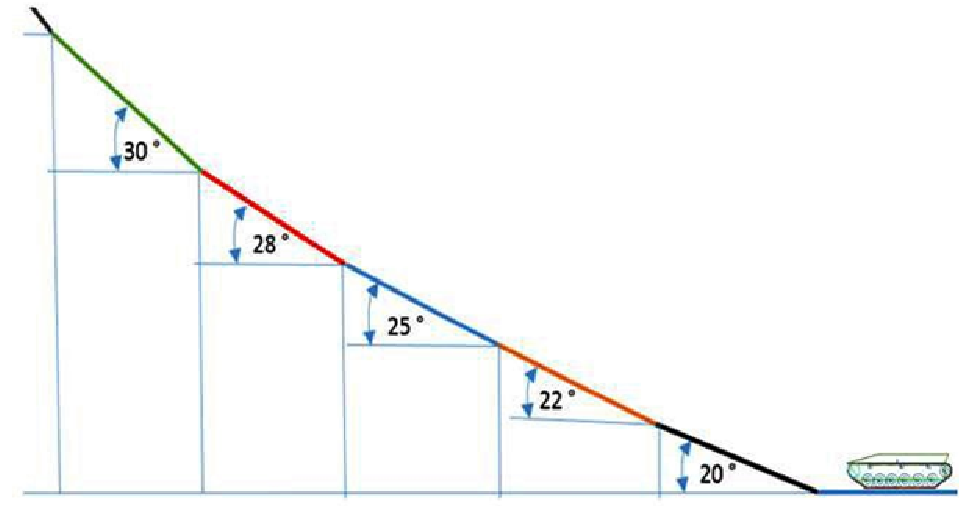

Fig. 1. Geometric structure of roadway model

\section{The model of the track link and the roadway contact}

Contact models describe the forces effect between a roadway and a track link. ADAMS Tracked Vehicle (AVT) Toolkit program unit offers 4 contact models of the roadway: they are the rigid roadway model, plastic - elastic roadway model, plastic roadway model and the model that is refinement by the user with a possibility to set measured experimental values. The rigid roadway contact model is described by the impact force:

where $k^{\prime}-$ stiffness, $\mathrm{N} \cdot \mathrm{m}^{-1}$

$$
F=-k^{\prime}\left(q-q_{0}\right)^{n}-c \dot{q}
$$

$q-q_{0}-$ geometric penetration of profiles, $\mathrm{mm}$

$c$ - damping, $\mathrm{W}$

$\dot{q}-$ velocity of the contacting body, $\mathrm{rad} \cdot \mathrm{s}^{-1}$

$n$-dynamic impact coefficient

\section{The analysis of maximum available angle of roadway inclination}

In this part of the article fulfilment of simulations and analysis is described. The analysis of the influence of changing the input parameters on the monitored parameters of the vehicle passability is described here. There were performed simulation calculations of the parameter values, which give a good picture about the vehicle behavior at different driving modes under different conditions. Changing input parameter simulation can be represented by the driving wheel angular velocity, roadway slope and the adhesion coefficient. Monitored properties can be, for example, the achieved roadway angle of inclination and maximum travelling vehicle distance to the moment of stopping the vehicle hull movement.

In the text below the results of the simulations calculations and analysis of the influence of angular driving wheel speed changes on the possibility to achieve a maximum travelling vehicle 
distance to the moment of stopping the vehicle hull movement are described. This form of testing is used because it is cheap and quick. All models were verified by help of experimental measuring in 2009. The verification measuring is described in [11]. The calculation results are not more confirmed than by using the next experimental measuring already.

\section{Results and discussion}

The following part of simulation calculations observed the simulation of the influence of the changes of the invasive vehicle speed changes by riding to slope on achieved roadway maximum vehicle distance to the moment of stopping the vehicle hull movement for loosing of track adhesion. The value of the adhesion coefficient was constant. The changes of the invasive vehicle speed by riding to slope were controled by setting of the angular speed driving wheel courses. Separate variants of set of the angular speed driving wheel courses $\omega$ were set from $12 \mathrm{rad} \cdot \mathrm{s}^{-1}$ to $32 \mathrm{rad} \cdot \mathrm{s}^{-1}$, by the step $2 \mathrm{rad} \cdot \mathrm{s}^{-1}$. The simulating calculations results of the angular velocity changes of the driving wheel at the achieved travelling vehicle distance maximum are introduced in the graph in Figure 2.

Figure 2 displays the influence of different angular speeds of the driving wheel in $\mathrm{rad} \cdot \mathrm{s}^{-1}$ on the possibility to achieve a travelling vehicle distance maximum in meters to the moment of stopping the vehicle hull movement depending on time. The angular speeds of the driving wheel were changed in limits from 12 into $32 \mathrm{rad} \cdot \mathrm{s}^{-1}$. The simulation result at the setting by the lowest angular driving wheel speed $\omega=12 \mathrm{rad} \cdot \mathrm{s}^{-1}$ is achieved at the travelling distance maximum $25.1 \mathrm{~m}$. It is the lowest value. The simulation results at setting of the highest angular speed of the driving wheel $\omega=32 \mathrm{rad} \cdot \mathrm{s}^{-1}$ is achieved at the travelling distance maximum $47.3 \mathrm{~m}$. It is the highest travelling distance maximum value.

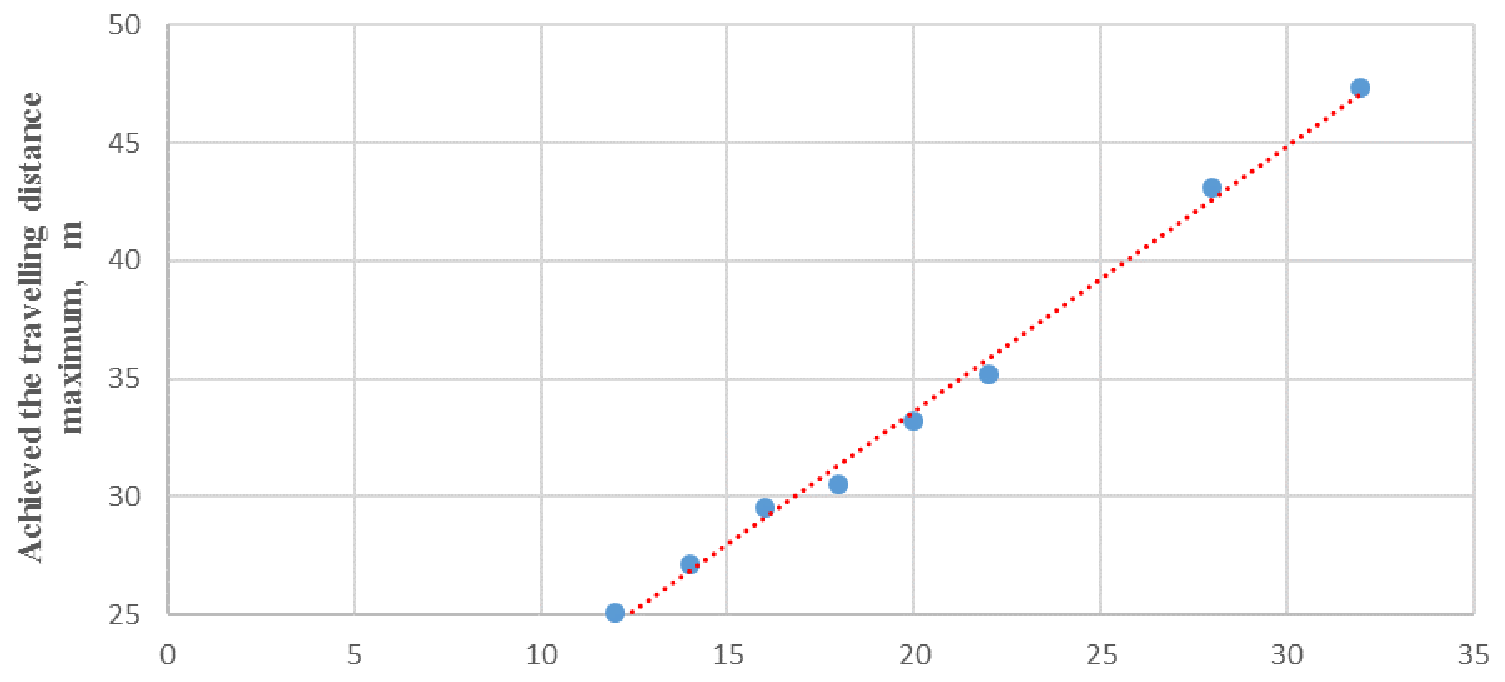

Angular velocity of driving wheel $\omega, \operatorname{rad} \cdot \mathrm{s}^{-1}$

Fig. 2. Influence of angular velocity changes of driving wheel at achieved travelling vehicle distance maximum

As it results from the graph in Figure 1, the highest rated value of the achieved travelling distance maximum of the vehicle ridden uphill is the distance at the highest angular driving wheel velocity.

Slightly different interpretation is offered by Figure 3, where the influence of the changes of the invasive vehicle speed at the achieved travelling distance maximum of the vehicle, which goes uphill, is clearly evident.

Fig. 3 displays the influence of different invasive vehicle speeds in $\mathrm{km} \cdot \mathrm{h}^{-1}$ on the possibility to achieve the travelling vehicle distance maximum in meters to the moment of stopping the vehicle hull movement. The invasive vehicle speeds were changed in limits from 13 into $33 \mathrm{~km} \cdot \mathrm{h}^{-1}$.

The simulation results at the setting by the lowest invasive vehicle speed $13 \mathrm{~km} \cdot \mathrm{h}^{-1}$ display the achieved travelling distance maximum $25.1 \mathrm{~m}$. It is the lowest value. The simulation results at the 
setting of the highest invasive vehicle speed $33 \mathrm{~km} \cdot \mathrm{h}^{-1}$ display the achieved travelling distance maximum $47.3 \mathrm{~m}$. It is the highest travelling distance maximum value.

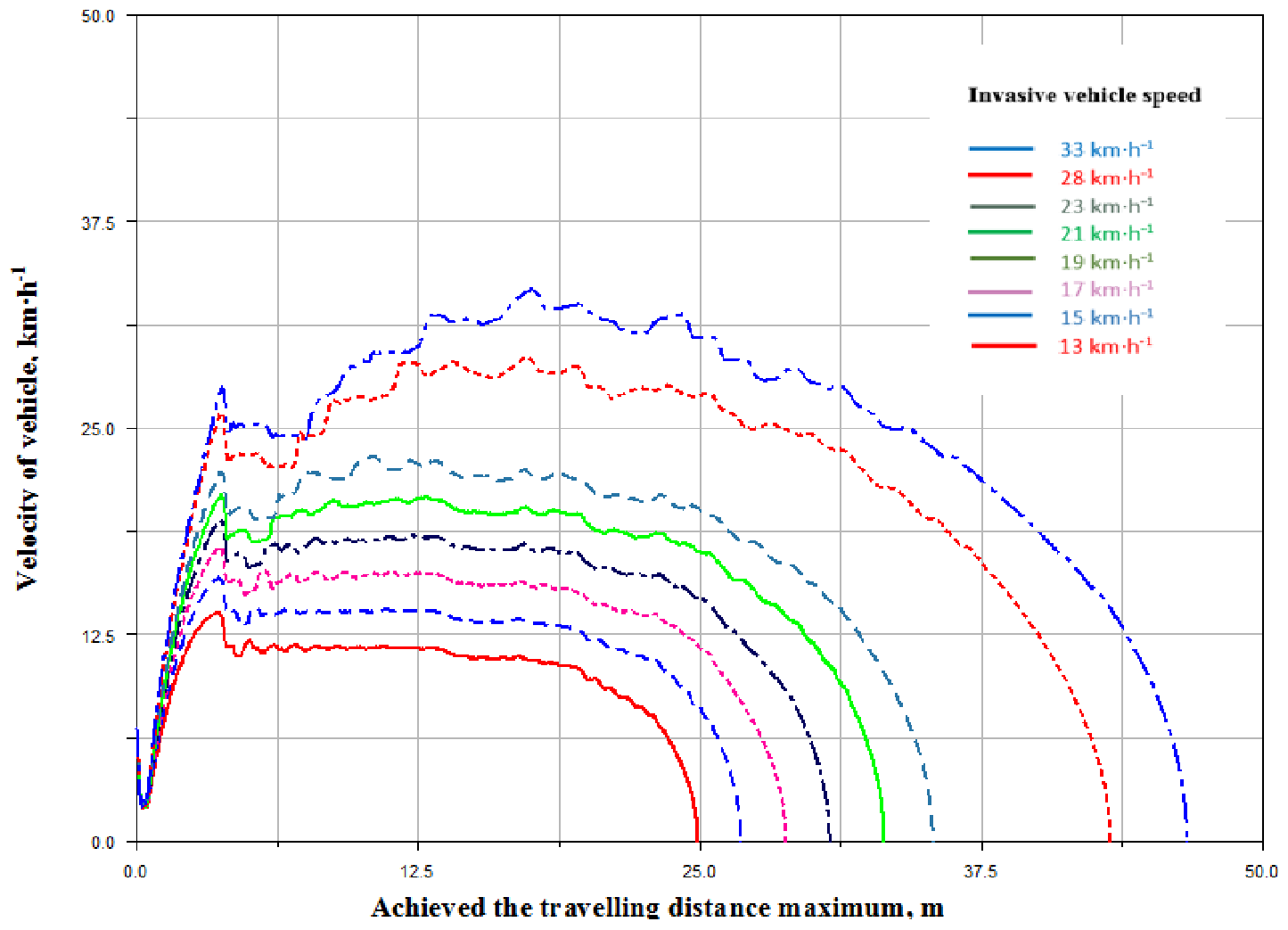

Fig. 3. Invasive vehicle speed influence on achieved travelling vehicle distance maximum

Generally it is possible to claim that the maximum of the achieved vehicle travelling distance by riding uphill is with the highest riding vehicle speed.

\section{Conclusions}

The aim of the simulations has been to acknowledge the possibility of the usage of analysis simulation results for the investigation of passability of a tracked vehicle. These simulations were executed by help of computing system Adams AVT. In this article the mathematic model composition for a tracked vehicle simulation riding uphill is described. Also, there are described the results of the simulation calculations of the vehicle driving uphill by changing conditions. The simulation and analysis results described the riding of the tracked vehicle BMP 1 uphill. The riding parameters are the angle of roadway climb and the invasive vehicle uphill speed. The results of simulation gained by help of computation system ADAMS AVT helped find the changes in the passability parameters very well. Consequently, the results of computational analysis and simulation are fully usable in practice in the field of engineering design work. We can tell that the simulation calculations results, conducted by help of computation simulation system ADAMS AVT is highly effective. It can serve in determination of the vehicle passability special properties in the cases, which are not in the framework of the basic vehicle design. These properties are not given exactly and it is necessary to investigate them using the physical practical test or computationally.

The main aim of the article was to acknowledge the possibility to use the results obtained by simulation calculations of the vehicle construction. These simulation results were gained by help of computing simulating system ADAMS AVT. The simulating calculations were done to find influence of the changes of the vehicle operation conditions.

\section{Acknowledgement}


The article was developed under effective supports of Partial intention for the development of organization "VÝZBROJ" (DZRO K-201) of Faculty of Military Technology of University of defence in Brno.

\section{References}

[1] Koucký M., Vališ D. Some aspects of sequential systems design. In Proceedings 17th ISSAT International Conference on Reliability and Quality in Design.: International Society of Science and Applied Technologies, Piscataway, 2011, pp. 62-66.

[2] Gerlici J., Lack T., Harušinec J. The Test Stand Load Modulus Implementation for the Realistic Railway Operation in the Laboratory Conditions. In: Manufacturing Technology, Vol. 13, FVTM UJEP, Ústí nad Labem, 2013, pp. 444-449.

[3] Rokyta L., Bilek O. Design of a Casting Die in CATIA. In: Manufacturing Technology, Vol. 12. FVTM UJEP, Ústí nad Labem, 2012.

[4] Svoboda M., Soukup J. Dynamic Measurement of Four-Axle Railway Wagon, In: Manufacturing Technology, Vol. 13, FVTM UJEP, Ústí nad Labem, 2013, pp. 552-558,

[5] Skočilas, J, Skočilasová B., Soukup J. Determination of the rheological properties of thin plate under transient vibration. In: Latin American Journal of Solids and Structures. Vol. 10, No. 1, Society of Brasil for Mechanics and Engineering. Brasil., 2013, pp. 187-193.

[6] Segl'a Š., Poláková Z., Hroncová D. Optimization of statical balancing of a manipulator with varying loads. In: Acta Mechanica Slovaca, Vol. 6, 2002, pp. 71-80.

[7] Klimenda, F., Svoboda, M., Rychlíková, L., Petrenko, A. Investigation of Vertical Vibration of a Vehicle Vodel Driving Through a Horizontal Curve. In: Manufacturing Technology, Vol. 15, FVTM UJEP, Ústí nad Labem, 2015, pp. 143-148.

[8] Nangolo F., Soukup J. The Effect of Asymmetry on Vertical Dynamic Response of Railway Vehicles. In: Manufacturing Technology, Vol. 14, FVTM UJEP, Ústí nad Labem, 2014, pp. 375-380.

[9] Lipták P., Jamrichová Z., Pešlová F., Stodola P., Stodola J. Tools and Processes for affordable Vehicles. In: ICMT'11: International Conference on military Technologies 2011. UO Brno, Czech Republic, 2011.

[10] Chalupa M., Věchet S., Houfek L. Methodology of the velocity measurement and acceleration of vehicle track link with usage of the GPS. University of defence, Brno, ČR, 2010.

[11]Chalupa M., Veverka J. Precising of vehicles handling valuation. Manufacturing Technology, Vol. 17, no. No. 3, FVTM UJEP, Ústí nad Labem, 2017, pp. 312-319.

[12] Chalupa M., Vlach R. Methodology of the data collection for verification of the BMP -2 track for computing system ProMechanica. University of defence, Brno, ČR, 2009. 